\title{
ПУТИ РАЗВИТИЯ ЛЕВОРАДИКАЛЬНЫХ ПАРТИЙ В СТРАНАХ ЕВРОПЕЙСКОГО СОЮЗА
}

Аннотация. Статья посвящена рассмотрению современных леворадикальных партий стран Европейского союза в сравнительной перспективе. Объектом исследования являются леворадикальные партии в странах Европейского союза. Предмет исследования - пути трансформации леворадикальных партий в странах ЕС с конца 1980-х годов до настоящего времени. Цель состоит в изучении современного состояния леворадикальных партий в странах Европейского союза и рассмотрения их перспектив. Автор даёт определение леворадикальной партии, подробно рассматривает причины, повлиявшие на выбор того или иного пути развития партии, факторы, способствующие электоральному успеху европейских леворадикальных партий. Методологической основой исследования является сравнительный метод. Кроме этого, применяется анализ научной литературы по изучаемой проблеме, документов леворадикальных партий, результатов выборов. За последние 25 лет европейские леворадикальные партии прошли через период кризиса и трансформации. К настоящему времени они сумели адаптироваться к новым условиям и занять свою нишу в партийных системах европейских стран. Сложилось несколько типов леворадикальных партий. Актуальной задачей для них остаётся проведение глубокого анализа новых явлений и процессов в обществе и разработка современной программы, в которой высказывались бы представления о радикальных, но вместе с тем, реализуемых преобразованиях для построения общества, альтернативного ныне существующему. Ключевые слова: леворадикальные партии, Европейский союз, коммунистические партии, левый радикализм, левосоциалистические партии, левые, политические партии, экосоциалистические партии, посткоммунистические партии, крайне левые партии.

Abstract. The paper is devoted to the contemporary far-left parties in the EU member-states and their comparison. The research object is far-left parties in the European countries. The research subject is the ways of their transformation since the late 1980s till the present. The paper is aimed at studying the modern condition of far-left parties in the countries of the European Union and their prospects. The author defines a far-left party, describes the factors which influenced the way of its development and promoted the electoral success of the European far-left parties. The research methodology is based on the comparative method; the author also applies the analysis of the scientific literature in this sphere, party documents and election results. In the last 25 years European far-left parties have experienced the period of crisis and transformation. By the present moment they've managed to adapt to the new conditions and to fine their niche within the European party systems. Several types of far-left parties have formed. They still need to analyze the new social phenomena and processes and to develop the modern programme which would reflect the ideas about radical but realizable transformations to form the society which would be an alternative to the existing one.

Key words: far-left parties, European Union, communist parties, radical left, left socialist parties, left, political parties, ecosocialist parties, post-communist parties, far-left paties.

$\mathrm{B}$ настоящее время в странах Европейского союза насчитывается более 60 леворадикальных партий [1, с. 38], довольно сильно отличающихся друг от друга по своим программным установкам, численности, степени влияния, организационным представлениям, стратегии и тактике действий. Вместе с тем, можно констатировать, что они обладают достаточной близостью взглядов, чтобы их можно было определить как отдельное партийное семейство [6; 12, с.4].

В современной политической науке не сложилось единого определения понятия «леворадикальная партия» и используется несколько различных, хотя и отчасти пересекающихся подходов $[6,7,11]$. К числу европейских леворадикальных партий относятся партии, расположенные в политическом спектре слева от социал-демократиче- ских и социалистических партий. Их объединяет критическое отношение к современному капиталистическому порядку и отстаивание необходимости радикальных подходов к решению экономических, политических и социальных проблем. Британский исследователь Л. Марч отмечает, что современные леворадикальные партии являются «радикальными» в том смысле, что они, во-первых, отвергают основные социально-экономические структуры и ценности современного капитализма (начиная с неприятия общества потребления и неолиберализма и заканчивая оппозицией по отношению к частной собственности); во-вторых, выступают за коренную трансформацию современной либеральной демократии, призывая к развитию альтернативных экономических и властных структур, в частности, прямой демократии. Они являются «левыми», пре- 
жде всего, потому, что определяют экономическое неравенство в качестве основы существующего политического и социального устройства, считая одним из приоритетов в своей деятельности отстаивание коллективных экономических и социальных прав. Кроме этого, они полагают, что национальные социально-политические проблемы имеют глобальные структурные причины, такие как «империализм» и «глобализация» $[11$, с.25]. Чешские исследователи В. Копечек и Л. Хлоушек предлагают включить в определение леворадикальных партий также следующие признаки: антиамериканизм, антиглобализм, противостояние НАТО и отрицание европейской интеграции в той или иной степени [7, с. 46]. По мнению немецкой исследовательницы К. Хильдебрандт, общими чертами всех леворадикальных партий являются решительная критика неолиберализма и милитаризма и стремление к преобразованию или преодолению существующей системы для создания общества, характеризующегося большей социальной справедливостью, демократизмом, миролюбием, заботой о сохранении окружающей среды [6].

Ещё одним критерием принадлежности партии к леворадикальному семейству является вхождение партии в одно из европейских межпартийных объединений $[1$, с. $38 ; 4$, с.7]: Партию европейских левых (ПЕЛ), Северный альянс зеленых и левых (САЗЛ), «Инициативу коммунистических и рабочих партий» (ИНИЦИАТИВА), объединение «Европейские антикапиталистические левые» (ЕАКЛ) или в состав политической группы «Европейские объединённые левые - Лево-зеленые севера» (ЕОЛ/ЛЗС) в Европарламенте.

Исторически леворадикальное движение не было единым и монолитным, представляя совокупность различных, порой враждующих партий и организаций. Наиболее успешными леворадикальными партиями в Европе на протяжении большей части XX в. были коммунистические. После распада СССР и крушения социализма в странах Восточной Европы под вопросом оказалось само существование леворадикальных партий в странах Европы. В первую очередь, это затронуло коммунистические партии, которые оказались в идейном и организационном кризисе. Они должны были пересмотреть своё идеологическое наследие и организационную модель, чтобы адаптироваться к новым политическим условиям $[11$, с.5].

Так, часть из них решила отказаться от коммунистической идеологии и продолжить своё развитие в качестве некоммунистических леворадикальных партий. Примерами можно назвать Коммунистическую партию Финляндии и шведскую Левую партию - Коммунисты, которые изменили свои названия на Левый союз и Левую партию соответственно. В Германии, после объединения страны, Социалистическая единая партия Германии (СЕПГ) перешла на позиции демократического социализма и была преобразована в Партию демократического социализма. В 2007 г. в результате объединения с партией «Труд и социальная справедливость - Избирательная альтернатива» была создана новая партия «Левые». Эти партии успешно прошли процесс адаптации к новым реалиям, стабильно завоёвывая места в национальных парламентах и Европарламенте.

Многие другие - в их числе большинство бывших правящих коммунистических партий в странах Восточной Европы, за исключением Чехии, - были преобразованы в социал-демократические и социалистические партии. В Западной Европе примером является Итальянская коммунистическая партия, которая эволюционировала в Демократическую партию левых, порвавшую с коммунистической идеологией и перешедшую на социал-демократические позиции, и, в конечном счёте, в нынешнюю Демократическую партию, отказавшуюся даже от социал-демократических установок. Коммунисты, не согласные с решениями руководства партии, создали Партию коммунистического возрождения, из которой, в свою очередь, в 1998 г. выделилась Партия Итальянских коммунистов (с конца 2014 г. - Коммунистическая партия Италии).

Некоторые коммунистические партии перестали существовать в качестве отдельных партий и стали частью коалиций левосоциалистической направленности. Так, Коммунистическая партия Нидерландов была распущена в 1991 г. для того, чтобы вместе с тремя другими левыми организациями создать новую партию Зелёные левые, занимающую позиции экосоциализма и либертарного социализма. Другой вариант - создание так называемых «широких левых» партий. Примерами таких партий являются Красно-зелёная коалиция, созданная в Дании на основе Компартии, партии Левых социалистов и троцкистской Социалистической рабочей партии, и португальский Левый блок, сформированный в 1999 г. как коалиция из трёх небольших леворадикальных организаций троцкистской Революционной социалистической партии, бывшего маоистского Народного демократического союза и Революционного фронта левых. Самым успешным примером создания широкой коалиции леворадикальных партий стала образованная в 2004 г. в Греции Коалиция радикальных левых (СИРИЗА), в 2013 г. преобразованная в единую партию. В неё вошли левые партии еврокоммунистической, маоистской, троцкистской, экологической и левосоциалистической направленности, несогласные с ортодоксальной линией Коммунистической партии Греции. 
Некоторые коммунистические партии участвуют в выборах, возглавляя постоянные выборные коалиции, одновременно сохраняя организационную и идеологическую автономию. Так, ещё в 1986 г. в Испании вокруг Компартии была создана коалиция «Объединённые левые», в состав которой входит ряд политических партий и организаций, региональные партии и отдельные граждане. В 1987 г. в Португалии, при ведущей роли Коммунистической партии, сложилась Коалиция демократического единства, в которую также входит экологическая партия «Зелёные». У каждого из субъектов этой коалиции есть своя собственная группа в парламенте, и он официально считается отдельной партией. В 2008 г., первоначально для участия в выборах в Европейский парламент, вокруг Французской коммунистической партии был создан альянс Левый фронт, куда также вошли Левая партия, Коммунистическая партия Реюньона, «Унитарные левые» и ряд более мелких левых партий и групп.

Другой вариант - это вхождение леворадикальной партии в коалицию в качестве второстепенного союзника социал-демократической партии, что позволяет ей получить некоторое парламентское представительство. Примерами являются Болгарская коммунистическая партия, которая участвует в выборах в составе «Коалиции за Болгарию», возглавляемой Болгарской социалистической партией, и Социалистическая партия Латвии, чьи кандидаты на выборах 2014 г. шли по списку Социал-демократической партии «Согласие».

Наконец, многие партии сохранили свои прежние названия и идентичности, хотя, так или иначе, были вынуждены приспосабливаться к новым политическим условиям. Для коммунистических партий можно выделить два основных пути: отстаивание ортодоксальных марксистско-ленинских позиций либо переход на позиции «реформированного» коммунизма.

Ряд партий - в первую очередь, Коммунистическая партия Греции (КПГ) и Португальская коммунистическая партия (ПКП) - не сочли необходимым серьезно корректировать свои программные основы и сохранили свою приверженность марксизму-ленинизму. В свою очередь, Коммунистическая партия Чехии и Моравии (КПЧМ), Коммунистическая партия Испании (КПИ), Французская коммунистическая партия (ФКП), Прогрессивная партия трудового народа Кипра (АКЭЛ) и некоторые другие изменили свои программные положения в сторону отказа от ориентации на насильственные способы свержения капиталистического строя, провозгласив себя сторонниками его постепенного реформирования в интересах трудящихся. Отдельно стоит упомянуть о двух бывших маоистских коммунистических партиях Партии труда Бельгии и нидерландской Социалистической партии, созданных в 1970-х гг. Если Партия труда Бельгии постепенно эволюционировала от маоизма к марксистско-ленинской идеологии, а затем (после 2008 г.) - к «реформированному» коммунизму, то голландские социалисты полностью отказались от марксизма-ленинизма уже в 1991 г., перейдя на левопопулистские, левосоциалистические позиции.

Таким образом, к настоящему времени европейские леворадикальные партии сумели адаптироваться к новым условиям и занять свою нишу в партийных системах европейских стран. Сложилось несколько типов леворадикальных партий - ортодоксальные и реформированные коммунистические, левосоциалистические, экосоциалистические [2, 3, с. 554 - 586; 5; 10, с. 18-19]. Леворадикальные партии участвовали в последних парламентских выборах в 26 странах Европейского союза (кроме Мальты и Польши), их поддержка колеблется от менее чем 1\% избирателей в таких странах, как Венгрия, Румыния, Словакия и Эстония, до общего результата более чем $40 \%$ - в Греции, более $30 \%$ - на Кипре, более $20 \%$ - в Испании, более $10 \%$ - в Ирландии, Португалии и Чехии. На настоящий момент (начало февраля 2016 г.) леворадикальные партии представлены хотя бы одним депутатом в национальных парламентах 18 странчленов ЕС.

В таблице 1 приводятся результаты леворадикальных партий стран ЕС, получивших парламентское представительство по итогам последних национальных выборов [13].

Большую роль в принятии того или иного пути развития сыграли внутренние традиции партии и особенности партийной системы страны. Можно проследить закономерность, что если коммунистическая партия ещё в 1960-1970 гг. приняла реформистскую, еврокоммунистическую направленность (как коммунистические партии Скандинавских стран или Итальянская коммунистическая партия), то им было легче принять новую, посткоммунистическую идентичность - социал-демократическую или левосоциалистическую. Отказ от коммунистической идеологии и переход на социалдемократические позиции был логичен для компартий Восточной Европы и Италии, где существующие социал-демократические партии были слабы. Партии, которые предприняли реформы, когда они уже находились в глубоком упадке (например, Коммунистическая партия Великобритании) фактически исчезли, и сильных леворадикальных партий в этих странах с того момента не возникло.

Тем не менее, в ряде стран позиции коммунистических партий достаточно стабильны, хотя их 


\section{Леворадикальные партии в национальных парламентах стран-членов ЕС} (по состоянию на февраль 2016 г.)

\begin{tabular}{|c|c|c|c|c|c|c|c|}
\hline Страна & \multicolumn{2}{|c|}{ Партия / Избирательная коалиция } & $\begin{array}{l}\text { Идеологическая } \\
\text { направленность }\end{array}$ & $\begin{array}{c}\text { Европейская } \\
\text { партия / } \\
\text { европейское } \\
\text { партийное } \\
\text { объединение }\end{array}$ & $\begin{array}{c}\% \\
\text { голосов }\end{array}$ & $\begin{array}{c}\text { Полу- } \\
\text { ченное } \\
\text { место } \\
\text { на вы- } \\
\text { борах }\end{array}$ & $\begin{array}{c}\text { Год } \\
\text { прове- } \\
\text { дения } \\
\text { выбо- } \\
\text { ров } \\
\end{array}$ \\
\hline Бельгия & \multicolumn{2}{|l|}{ Партия труда Бельгии } & $\begin{array}{c}\text { реформированный } \\
\text { коммунизм }\end{array}$ & - & 3,72 & 9 & 2014 \\
\hline Болгария & \multicolumn{2}{|c|}{$\begin{array}{l}\text { Коммунистическая партия Болгарии } \\
\text { (по списку Болгарской социалистической партии) }\end{array}$} & $\begin{array}{c}\text { ортодоксальный } \\
\text { коммунизм }\end{array}$ & - & $15,4^{1}$ & 2 & 2014 \\
\hline $\begin{array}{l}\text { Великобритания } \\
\text { (Северная } \\
\text { Ирландия) } \\
\end{array}$ & \multicolumn{2}{|l|}{ Шинн Фейн } & левый социализм & - & $\begin{array}{c}0,6 \\
(24,5)^{2}\end{array}$ & $6(2)$ & 2015 \\
\hline Германия & \multicolumn{2}{|l|}{ Левые } & левый социализм & ПЕЛ & 8,6 & 3 & 2013 \\
\hline \multirow[t]{2}{*}{ Греция } & \multicolumn{2}{|c|}{ Коалиция радикальных левых (СИРИЗА) } & левый социализм & $\begin{array}{l}\text { ПЕЛ, ЕАКЛ } \\
\text { (набл.) }\end{array}$ & 35,46 & 1 & \multirow[t]{2}{*}{2015} \\
\hline & \multicolumn{2}{|c|}{ Коммунистическая партия Греции } & $\begin{array}{c}\text { ортодоксальный } \\
\text { коммунизм }\end{array}$ & ИНИЦИАТИВА & 5,47 & 5 & \\
\hline Дания & \multicolumn{2}{|l|}{ Красно-зелёная коалиция } & экосоциализм & ПЕЛ & 7,8 & 4 & 2015 \\
\hline \multirow[t]{3}{*}{ Ирландия } & \multicolumn{2}{|l|}{ Шинн Фейн } & левый социализм & - & 9,9 & 4 & \multirow[t]{3}{*}{2011} \\
\hline & \multicolumn{2}{|c|}{ Социалистическая партия } & троцкизм & ЕАКЛ & 1,2 & 6 & \\
\hline & \multicolumn{2}{|c|}{ «Люди прежде, чем прибыль» } & левый социализм & ЕАКЛ & 1 & 7 & \\
\hline \multirow[t]{2}{*}{ Испания } & \multicolumn{2}{|l|}{ Подемос («Мы можем») } & левый социализм & - & 20,68 & 3 & \multirow[t]{2}{*}{2015} \\
\hline & $\begin{array}{l}\text { Объединённые левые } \\
\text { (в составе коалиции } \\
\text { «Объединённые левые- } \\
\text { Народное единство») }\end{array}$ & $\begin{array}{l}\text { Коммунистическая } \\
\text { партия Испании }\end{array}$ & $\begin{array}{c}\text { реформированный } \\
\text { коммунизм }\end{array}$ & ПЕЛ & $3,7 \%{ }^{3}$ & 5 & \\
\hline Кипр & \multicolumn{2}{|c|}{ Прогрессивная партия трудового народа } & $\begin{array}{c}\text { реформированный } \\
\text { коммунизм } \\
\end{array}$ & ПЕЛ (набл.) & 32,67 & 2 & 2011 \\
\hline Латвия & \multicolumn{2}{|c|}{$\begin{array}{l}\text { Социалистическая партия Латвии (по списку } \\
\text { Социал-демократической партии «Согласие») }\end{array}$} & $\begin{array}{c}\text { ортодоксальный } \\
\text { коммунизм }\end{array}$ & ИНИЦИАТИВА & $28,36^{4}$ & 1 & 2014 \\
\hline Люксембург & \multicolumn{2}{|l|}{ Левые } & левый социализм & ПЕЛ, ЕАКЛ & 4,92 & 6 & 2013 \\
\hline Нидерданды & \multicolumn{2}{|l|}{ Социалистическая партия } & левый социализм & - & 9,7 & 4 & 2012 \\
\hline \multirow[t]{2}{*}{ Португалия } & \multicolumn{2}{|l|}{ Левый блок } & левый социализм & ПЕЛ, ЕАКЛ & 10,2 & 3 & \multirow[t]{2}{*}{2015} \\
\hline & \multicolumn{2}{|c|}{$\begin{array}{l}\text { Португальская коммунистическая партия (в со- } \\
\text { ставе Коалиции демократического единства) }\end{array}$} & $\begin{array}{c}\text { ортодоксальный } \\
\text { коммунизм }\end{array}$ & - & $8,3^{5}$ & 4 & \\
\hline Словения & \multicolumn{2}{|l|}{ Объединенные левые } & левый социализм & ПЕЛ & 5,97 & 5 & 2014 \\
\hline Финляндия & \multicolumn{2}{|l|}{ Левый союз } & $\begin{array}{c}\text { левый социализм, } \\
\text { экосоциализм }\end{array}$ & ПЕЛ & 7,13 & 6 & 2015 \\
\hline \multirow[t]{3}{*}{ Франция } & \multirow[t]{3}{*}{ Левый фронт } & $\begin{array}{l}\text { Французская коммуни- } \\
\text { стическая партия }\end{array}$ & $\begin{array}{c}\text { реформированный } \\
\text { коммунизм }\end{array}$ & ПЕЛ & \multirow[t]{3}{*}{6.91} & \multirow[t]{3}{*}{4} & 2012 \\
\hline & & $\begin{array}{l}\text { Федерация за соци- } \\
\text { альную и экологиче- } \\
\text { скую альтернативу }\end{array}$ & экосоциализм & - & & & \\
\hline & & Левая партия & левый социализм & ПЕЛ & & & \\
\hline Чехия & Коммунистическая парт & ия Чехии и Моравии & $\begin{array}{c}\text { реформированный } \\
\text { коммунизм }\end{array}$ & ПЕЛ (набл.) & 14,91 & 3 & 2013 \\
\hline Швеция & Левая партия & & $\begin{array}{c}\text { левый социализм } \\
\text { экосоциализм }\end{array}$ & САЗЛ & 5,72 & 6 & 2014 \\
\hline
\end{tabular}

${ }^{1}$ Результат коалиции Болгарская социалистическая партия - Левые Болгарии

2 Результат по Северной Ирландии

${ }^{3}$ Результат коалиции «Объединённые левые - Народное единство»

${ }^{4}$ Результат Социал-демократической партии «Согласие», по списку которой были избраны депутаты от Социалистической партии

${ }^{5}$ Результат Коалиции демократического единства

поддержка остаётся ниже уровня 1980-х гг. (например, КПГ, ПКП, КПИ). Главным исключением среди коммунистических партий является Прогрессивная партия трудового народа Кипра. Её успех можно объяснить некоторыми особенностями политической жизни страны и партийной организации, такими как наличие активной пролетарской субкультуры, традициями массового членства в партии, строгой партийной дисциплиной, соединенной с относительной идеологической умеренностью [5]. Но, вместе с тем, коммунистические партии испытали и наибольшие электоральные потери среди всех леворадикальных партий, и в ряде стран - например, Италии и Словакии - их долгосрочное будущее как значимых партий оказывается под вопросом. 
Наиболее успешным в электоральном плане для леворадикальных партий оказался выбор стратегии, при которой партия сохраняла бы элементы радикальной идентичности и отличия от социал-демократии, но при этом претерпела значительную внутреннюю идеологическую и стратегическую эволюцию. Левосоциалистические и широкие левые партии, например, шведская Левая партия, финский Левый союз, португальский Левый блок, в целом, имеют стабильную поддержку, в то же время можно выделить несколько случаев (например, Социалистическая партия Нидерландов, Шинн Фейн, германские «Левые»), когда их поддержка существенно увеличилась по сравнению с концом 1980-х - началом 1990-х гг. Отдельно строит отметить греческую «Коалицию радикальных левых» (СИРИЗА), которая увеличила свой результат на парламентских выборах с 4,6\% в 2012 г. до $36,34 \%$ в январе 2015 г.

Среди факторов, способствующих электоральному успеху леворадикальных партий, можно выделить тяжёлую социально-экономическую обстановку, высокий уровень протестных настроений, наличие социалистических традиций в стране и длительное предшествующее существование партии, отсутствие конкурирующих партий на протестном поле [9, с. 7-10].

Наиболее очевидной связью является историческая: успешные леворадикальные партии существуют сегодня там, где они были успешны в прошлом. Многие из партий имеют длительную историю и глубоко укоренены в обществе (например, КПГ, ПКП, АКЭЛ, КПЧМ), а недавно основанные партии часто опираются на более давние политико-культурные традиции партии-предшественницы (например, немецкие «Левые», ведущие свою историю от СЕПГ, имеют поддержку избирателей, главным образом, из восточно-германских федеральных земель). Важную роль для коммунистических и бывших коммунистических партий играют регионы «красного пояса», где их поддержка на выборах до сих пор остаётся много выше средней по стране (например, Крёз и Коррез во Франции, Болонья в Италии, Сетубал в Португалии). Даже очевидные исключения подтверждают это правило. Социалистическая партия Нидерландов впервые вошла в национальный парламент только в 1994 г., но до этого она уже создала себе известность и авторитет на муниципальном и региональном уровне путём работы с избирателями по принципу «от двери к двери» и установления связей с различными общественными объединениями и социальными движениями.

Утверждение, что экономические условия оказывают влияние на результаты партий на выборах, подтверждается многочисленными эмпирически- ми исследованиями [8]. Леворадикальные партии придают большое значение таким социальным и экономическим вопросам, как обеспечение полной занятости, противостояние или ограничение приватизации, расширение прав профсоюзов, поэтому есть основания ожидать, что они могут укрепить свою поддержку в условиях экономического спада и увеличения безработицы. К примеру, принятие правительством Греции нового соглашения с европейскими кредиторами стало одной из причин успеха СИРИЗА на парламентских выборах в январе 2015 г., которая в своей предвыборной программе сделала ставку на обещания отменить программу жёсткой экономии и списать часть огромного долга страны. Важным фактором для её победы было и сотрудничество с широким социальным протестным движением.

Вместе с тем, леворадикальным партиям приходится делить место в протесте с зелеными и праворадикальными партиями. Наличие успешных зелёных партий в Финляндии и Нидерландах является одной из причин того, что леворадикальные партии выступают там более слабо, чем в Дании, где отсутствие «зелёного» конкурента позволяет Красно-зелёной коалиции заявить о своих экосоциалистических взглядах. Кроме этого, важную роль для успеха леворадикальных партий играет использование ими смещения многих социал-демократических партий в сторону центра, при котором они получают возможность заявить о «предательстве» социал-демократами своих традиционных социалистических принципов и избирателей и встать на их защиту. Примечательно, что одна из партий-предшественниц германских «Левых» - «Труд и социальная справедливость Избирательная альтернатива» - была образована непосредственно социал-демократами, вышедшими из СДПГ.

Безусловно, нельзя утверждать, что леворадикальные партии лишь пассивно реагируют на изменения во внешней среде. Собственный выбор, сделанный партией, в значительной степени определяет ту степень, в которой он может реагировать на внешние факторы. Так, Л. Марч отмечает тот факт, что леворадикальные партии, сумевшие успешно адаптироваться к новым условиям, редко опираются на абстрактные идеологические доктрины и лозунги и стремятся объединить все леворадикальные направления под флагом противостояния неолиберализму, преодолев внутренний догматизм [9, с.10]. Кроме этого, в наиболее электорально эффективных партиях поменялась и роль руководителя партии: на место «непреклонных» деятелей традиционных коммунистических партий, таких как Жорж Марше и Алвару Куньял, пришли современные лидеры, умеющие работать 
на публику и демонстрировать недогматические, но принципиальные позиции, которые признаются «харизматическими» даже своими политическими оппонентами и критиками $[9$, с.10]. В числе таких лидеров можно назвать лидера фракции «Левых» в Бундестаге Грегора Гизи и лидера СИРИЗА Алексиса Ципраса.

Вместе с тем, надо отметить, что прежние идеологические дискуссии и противоречия хоть и ослабли, но не исчезли, и дают о себе знать внутри отдельных партий, приводя к их расколам, во враждебных отношениях между несколькими леворадикальными партиями в одной стране, и на уровне всего ЕС, где леворадикальные партии не могут выработать общую согласованную позицию и проводить общий политический курс. Отмечая успехи некоммунистических леворадикальных партий, не стоит сбрасывать со счетов и компартии как носителей собственных идейных установок, стратегии и тактики действий, собственного видения будущего. Примеры АКЭЛ, КПГ, ПКП, КПЧМ, на протяжении многих лет сохраняющих стабильную поддержку, позволяют если не опровергнуть, то поставить под сомнение выводы о том, что ев- ропейские коммунистические партии не имеют реальной перспективы.

Подводя итоги, можно заключить, что за последние 25 лет европейские леворадикальные партии прошли через период кризиса и трансформации. В настоящее время положение отдельных партий заметно различается от страны к стране, но между ними существует множество точек соприкосновения. Все леворадикальные партии в Европе выступают против неолиберальной политики правящих европейских элит и за создание общества, характеризующегося большей социальной справедливостью, демократизмом, миролюбием, заботой о сохранении окружающей среды. Но этого недостаточно, чтобы сплотить людей вокруг объединяющего альтернативного проекта, который смог бы бросить вызов неолиберализму. Актуальной задачей леворадикальных партий остаётся проведение глубокого анализа новых явлений и процессов в обществе и разработка современной программы, в которой высказывались бы представления о радикальных, но вместе с тем, реализуемых преобразованиях для построения общества, альтернативного ныне существующему.

\section{Библиография:}

1. Жирнов О. А. «Новые левые» в Европе (Обзор). // Актуальные проблемы Европы. - М., 2012. - №2. - С. 37-84.

2. Швейцер В.Я. Новые левые в современной Европе // Европейские левые на рубеже тысячелетий. Колл. авторов. Под общ. ред. В. Я. Швейцера. - М.: ИЕ РАН - Издательство «ОГНИ ТД», 2005. - С. 19-28.

3. Backes, U., Moreau P. Communist and Post-Communist Parties in Europe. -Göttingen: Vandenhoeck \& Ruprecht, 2008. $660 \mathrm{p}$.

4. Daiber B., Hildebrandt C., Striethorst A. (Ed.). From Revolution to Coalition - Radical Left Parties in Europe. - Berlin: RosaLuxemburg-Foundation, 2012. - 384 p.

5. $\quad$ Dunphy R., Bale T. Red Flag Still Flying? Explaining AKEL - Cyprus' Communist Anomaly. // Party Politics, 2007. Vol. 13. - №3. - P. 287-304.

6. Hildebrandt C. Fragmentation and pluralism of Leftist parties in Europe. - Berlin. Rosa Luxemburg Stiftung, 2010. Mode of access: http://transform-network.net/uploads/tx_news/Hildebrandt_Fragment.pdf

7. Hloušek V., Kopeček L. Origin, ideology and transformation of political parties: East-Central and Western Europe compared. - Ashgate Publishing. 2010. - 263 p.

8. Lewis-Beck M., Paldam M. Economic voting: An introduction. // Electoral Studies, 2000. - Vol. 19. - № 2-3. - P. $113-121$.

9. March L. Contemporary Far Left Parties in Europe. From Marxism to the Mainstream? // International policy analysis. - Berlin: Friedrich-Ebert-Stiftung. - 2008. - November. - 20 p. - Mode of access: http://library.fes.de/pdf-files/id/ ipa/05818.pdf

10. March L. Radical Left Parties in Europe. - London: Routledge, 2011. - 274 p.

11. March L., Mudde C. What's Left of the Radical Left? The European Radical Left After 1989: Decline and Mutation. // Comparative European Politics. - London, Palgrave Macmillan, 2005. - Vol. 3.-№1. - P. 23 - 49.

12. March L., Rommerskirchen, C. Out of Left Field?: Explaining the Variable Electoral Success of European Radical Left Parties. // Party Politics, 2015. - Vol. 21. - No. 1. - Mode of access: http://www.research.ed.ac.uk/portal/files/14646791/Out_of_ left_field.pdf

13. Parties and Elections in Europe. / The database about parliamentary elections and political parties in Europe. - Mode of access: http://www.parties-and-elections.eu/

\section{References (transliterated):}

1. Zhirnov 0. A. «Novye levye» v Evrope (Obzor). // Aktual'nye problemy Evropy. - M., 2012. - №2. - S. 37-84.

2. Shveitser V.Ya. Novye levye v sovremennoi Evrope // Evropeiskie levye na rubezhe tysyacheletii. Koll. avtorov. Pod obshch. red. V. Ya. Shveitsera. - M.: IE RAN - Izdatel'stvo «OGNI TD», 2005. - S. 19-28.

3. Backes, U., Moreau P. Communist and Post-Communist Parties in Europe. -Göttingen: Vandenhoeck \& Ruprecht, 2008. $660 \mathrm{p}$.

4. Daiber B., Hildebrandt C., Striethorst A. (Ed.). From Revolution to Coalition - Radical Left Parties in Europe. - Berlin: RosaLuxemburg-Foundation, 2012. - 384 p. 
5. Dunphy R., Bale T. Red Flag Still Flying? Explaining AKEL - Cyprus' Communist Anomaly. // Party Politics, 2007. Vol. 13. - №3. - P. 287-304.

6. Hildebrandt C. Fragmentation and pluralism of Leftist parties in Europe. - Berlin. Rosa Luxemburg Stiftung, 2010. Mode of access: http://transform-network.net/uploads/tx_news/Hildebrandt_Fragment.pdf

7. Hloušek V., Kopeček L. Origin, ideology and transformation of political parties: East-Central and Western Europe compared. - Ashgate Publishing. 2010. - 263 p.

8. Lewis-Beck M., Paldam M. Economic voting: An introduction. // Electoral Studies, 2000. - Vol. 19. - № 2-3. - P. $113-121$.

9. March L. Contemporary Far Left Parties in Europe. From Marxism to the Mainstream? // International policy analysis. Berlin: Friedrich-Ebert-Stiftung. - 2008. - November. - 20 p. - Mode of access: http://library.fes.de/pdf-files/id/ ipa/05818.pdf

10. March L. Radical Left Parties in Europe. - London: Routledge, 2011. - 274 p.

11. March L., Mudde C. What's Left of the Radical Left? The European Radical Left After 1989: Decline and Mutation. // Comparative European Politics. - London, Palgrave Macmillan, 2005. - Vol. 3.-№1. - P. 23 - 49.

12. March L., Rommerskirchen, C. Out of Left Field?: Explaining the Variable Electoral Success of European Radical Left Parties.// Party Politics, 2015. - Vol. 21. - No. 1. - Mode of access: http://www.research.ed.ac.uk/portal/files/14646791/Out_of_ left_field.pdf

13. Parties and Elections in Europe. / The database about parliamentary elections and political parties in Europe. - Mode of access: http://www.parties-and-elections.eu/ 